\title{
Do European business cycles look like one?*
}

\author{
Maximo Camacho ${ }^{\dagger}$ \\ Universidad de Murcia \\ mcamacho@um.es
}

\author{
Gabriel Perez-Quiros \\ Banco de España \\ gabriel.perez@bde.es
}

\author{
Lorena Saiz \\ Bank of Spain \\ lsaiz@bde.es
}

\begin{abstract}
This paper provides a comprehensive framework to analyze business cycle features other than synchronization. We use stationary bootstrap and model-based clustering methods to analyze similarities and differences among the European cycles. We find evidence that the length, deep and shape of cycles differ across European countries and that these differences are not decreasing over time. Finally, even though we find some correlation between business cycle synchronization and characteristics, there is important information in the characteristics that is not captured by the synchronization measures.
\end{abstract}

Keywords: Business cycle characteristics, economic integration, European Union enlargement.

JEL Classification: E32, F02, C22

${ }^{*}$ We thank the editor, two anonymous referees and seminar participants at Bank of Spain, 8th CEPR/ESI annual conference and 9th World Congress of the Econometric Society for helpful comments and suggestions. Remaining errors are our own responsibility. Maximo Camacho thanks the financial support of the project SEJ2006-15172. The views in this paper are those of the authors and do not represent the views of the Bank of Spain or the Eurosystem.

${ }^{\dagger}$ Corresponding Author: Universidad de Murcia, Facultad de Economia y Empresa, Departamento de Metodos Cuantitativos para la Economia, 30100, Murcia, Spain. E-mail: mcamacho@um.es. 


\section{Introduction}

In the literature on optimal economic unions, it is well known that joining a union does not necessarily imply an improvement for each of its members. From the point of view of business cycle researchers, the main cost of joining the union has to do with leaving the traditional economic stabilization policies to supranational authorities. The theoretical argument behind this reasoning is that stabilization decisions made at supranational levels could be optimal for the subset of countries with more homogeneous cycles but that they may be against the economic interest of countries with more atypical cycles. In the case of the European Union (EU), most members have left monetary decisions to the European Central Bank. Even for those countries that do not belong to the European Monetary Union (EMU), fiscal policies are restricted to the achievement of close-to-balance budget constraints that are imposed by the stability pacts. In this context, an increasing attention is being devoted to examine similarities and differences among the EU countries' business cycles.

Remarkably, most of these empirical studies have focused exclusively on just one feature of the business cycle dynamics: synchronization. According to these studies, more synchronized countries are expected to face smaller costs of joining the Union than those countries with relatively less synchronized cycles. Among many others, recent academic examples are Dueker and Wesche (2003), Darvas and Szapary (2005), Camacho, Perez-Quiros, and Saiz (2006), and the survey of de Haan, Inklaar and Jong-A-Pin (2007). In addition, relevant policymakers like Trichet (2001) when describing the evolution of the integration of European markets, only consider synchronization (correlation) to examine the degree of business cycle similarities.

Analysis of similarities and differences in business cycle characteristics other than synchronization has been minor and mainly descriptive. ${ }^{1}$ We propose that the evaluation of business cycle synchronization might be complemented with a careful analysis of the form of the cycles. Although synchronization of national business cycles is relevant to analyze the timing of stabilization policies, having synchronized cycles is a necessary but not sufficient condition to conclude that countries will exhibit low stabilization costs of joining the Union. For instance, within the existing literature on business cycle synchronization, countries with synchronized cycles do not face apparent costs of joining the Union in terms of their stabilization policies. However, if the shapes of their cycles are different, supranational policy reactions against recessions may be too accommodative for countries that change the business cycle phases sharply and too tight for countries whose state changes are

\footnotetext{
${ }^{1}$ We acknowledge two exceptions. Artis, Marcellino and Proietti (2005) study the business cycle characteristics of countries acceding the EU in 2004 using a different methodological approach. Krolzig and Toro (2005) simulate their estimated models for some EU countries to examine the characteristics of their estimated models.
} 
smooth. These policies may also last too long for countries with shorter duration of cycles and too short for countries with longer cycles. Finally, the strength of common stabilization policies may be insufficient for those countries with deeper cycles and disproportionate for countries with mild cycles.

Our paper contributes to the business cycle literature by offering a comprehensive framework to analyze business cycle characteristics other than synchronization. For this purpose, several statistical advances achieved in other areas have been adapted to the analysis of business cycles. On the one side, we adapt the stationary bootstrap method proposed by Politis and Romano (1994) to the analysis of the business cycle characteristics that are described in Harding and Pagan (2002a). In our opinion, this method can be used to overcome several criticisms of past studies on business cycle characteristics. In particular, the method reduces the dependence of the results to the possible existence of mild business cycle phases and incomplete cycles when analyzing short time series. On the other hand, we innovate in the statistical approach that has been used to compare business cycle characteristics across countries. To do this, we employ the model-based clustering method outlined in Fraley and Raftery (2002) to group countries in several clusters with similar business cycles characteristics.

With respect to the empirical contributions, we compare the business cycle characteristics of the countries that have recently joined the EU with those of the old members. This comparison is important since the new members are encouraged to qualify for participation in the Monetary Union. In addition, we ask whether all European business cycles cluster around a single set of characteristics or whether there are multiple clusters of countries with distinctly different cycles. Finally, we are pioneer in trying to relate the pairwise distances in business cycle characteristics with the distances in business cycle synchronization. Although statistically significant, the correlation between them is far from being perfect, leaving the business cycle characteristics to be determined by business cycle factors other than synchronization. These results questions the disproportionate attention that has been devoted to business cycle synchronization in contrast to other business cycle features.

The paper is structured as follows. Section 2 develops the framework to analyze business cycle characteristics. Section 3 describes the data, characterizes the business cycle of our sample of countries, studies the existence of an European cycle, and examines the relation between similitudes in business cycle features and business cycle synchronization among the EU economies. Section 4 concludes. 


\section{A framework to analyze business cycle characteristics}

In this study we consider classical business cycles, as in Harding and Pagan (2002a). This avoid the problem of detrending the series, that we would need if we considered growth cycles. However, all the analysis could easily be extended to consider other definitions of the cycle.

This section attempts to construct the statistical framework to analyze similarities and differences among the EU countries' business cycle characteristics. First, we select the appropriate set of features that we need to obtain a detailed description of the form of their cycles. Second, due to the potential dependence of the results on the turning point dates, we offer a robust method to obtain business cycle characteristics from time series. Finally, we describe a statistical framework to group related countries in clusters with similar business cycle characteristics.

\subsection{The key features to describe the business cycle}

The empirical literature on business cycles has identified a wide variety of business cycle characteristics. Among them, we want to select the minimum set of features being able to provide a complete description of the business cycle from the series of production. In this respect, Harding and Pagan (2002a) consider three relevant business cycle features, length, depth and shape, that are approximated by their measures of duration, amplitude, and excess, respectively.

With respect to the length of the cycles, they consider that the duration of an expansion corresponds to the time spent between the trough, that is the lowest level of activity and marks the end of a recession, and the following peak, that is the highest point of activity and marks the end of an expansion. Similarly, the duration of a recession is the time spent between a peak and the following trough.

In order to measure the depth of business cycle phases, we compare the log level of the time series at two consecutive turning points. In the case of expansions, one hundred times the amplitude represents the percentage that has been gained in terms of production. Alternatively, the amplitude may be interpreted as the percentage that have been lost in the case of recessions.

The last key dimension of the business cycle appearance is the shape. To consider this feature, the authors define a measure, called excess, that measures the departures of the actual time series path from the hypothetical path if the transition between two consecutive turning points was linear. $^{2}$ Defined in this way, the excess becomes an intuitive approximation to the second derivative

\footnotetext{
${ }^{2}$ For a given phase of the cycle, $i$, let $C_{i}, C_{T_{i}}$, and $A_{i}$ be the actual cumulative movements of the series, the triangular approximation to the cumulative movements, and the amplitude, respectively. We compute the excess as the averaged values of $C_{T_{i}}-C_{i}+0.5 A_{i}$, where the last term removes the bias that arises in using a sum of rectangles to approximate the area under the actual path. Harding and Pagan (2002a) use the same measure but
} 
of the series and allows us to examine the concavity or convexity of the business cycle phase. To illustrate the relation between the sign of the excess and the shape of the cycle, Figure 1 depicts the stylized pictures of typical expansions (top charts) and recessions (bottom charts). Convex (concave) actual paths are characterized by positive (negative) slopes and positive (negative) measures of excess, that are represented by the shaded areas. ${ }^{3}$

The excess may also be related to the degree of abruptness with which the time series enters to and exits from turning points. In convex expansions and concave recessions, actual paths exhibit gradual changes in the slope at the beginning of the phase, but they become abrupt as the end of the phase comes. By the contrary, in concave expansions and convex recessions, actual paths start the phase of the cycle with steep changes and end the phase smoothly.

\subsection{Dating turning points and business cycle analysis}

In empirical applications, it is worth noting that all of the previous measures of business cycle characteristics rely on having the appropriate turning point chronologies for each country. In the US, the National Bureau of Economic Research (NBER) Business Cycle Dating Committee has dated the expansions and recessions and its decisions have been generally recognized as the official business cycle dates. On the contrary, there is no widely accepted business cycle reference chronologies in other countries.

Dating the turning points in countries other than US has been the source of many initiatives, that can be broadly classified as nonparametric and parametric. Inside the nonparametric alternatives, the most popular one has been suggested by Bry and Boschan (1979). They develop an algorithm that isolates the local minima and maxima in time series, subject to reasonable constraints on both length and amplitude of expansions and contractions. ${ }^{4}$ Among other authors, Harding and Pagan (2002b), and Artis, Marcellino, and Proietti (2004) have suggested alternative refinements of the Bry-Boschan seminal dating algorithm. On the other hand, dating turning points through parametric models has gained considerable attention during the last fifteen years. Among the set of parametric specifications, the most widely used method to establish the different

divided by the duration. We prefer to use our definition just to isolate the effect of the measure of the shape from the possible error of the duration measure

${ }^{3}$ Note that Harding and Pagan (2002a) define excess as the area of the triangle minus the area of actual (see page 370) but they find an excess for expansions of 1.1. They interpret this positive value as evidence of the rapid recovery exhibited after recessions. However, rapid recovery with this definition in mind would mean negative excess for the expansions. We keep their formal definition, that coincides with their interpretation for the recessions but our sign is changed for the expansion periods.

${ }^{4}$ For example, they enforce minimum lengths of expansions and recessions, and ensure that peaks and troughs alternate. 
phases of business cycles has been the Markov switching specification of Hamilton (1989). However, other alternatives as the threshold autoregressive process of Tsay (1989), and the smooth transition autoregressive model of Teräsvirta (1994) have also been employed. ${ }^{5}$

Choosing a method among these proposals does not seem to be an easy task as none of them is exempt from problems. ${ }^{6}$ In any case, the dating methods usually face a high degree of uncertainty surrounding the signal estimates of some turning points. This leads to the fact that different methods provide the researchers with similar but not coincident business cycle chronologies. As it turns out, the results of the business cycle study may rely on subtle decisions about the dating mechanism adopted in the analysis. Examples of this inconsistency can be found throughout the literature. One significant example is Krozlig and Toro (2005) who find conflicting Italian business cycle chronologies from Markov switching and nonparametric dating methods, especially at identifying the last two recessions. Another example is the different business cycle chronologies from Artis et al. (2005) and Camacho et al. (2006), which come almost entirely from refinements to the Bry-Boschan method applied by the former authors. ${ }^{7}$

Most of the differences among the business cycle chronologies that are obtained from these methodologies are associated to the existence of the so-called mild recessions. If our interest is just on synchronization, the question of including or not mild recessions in the final business cycle chronologies will probably leads to negligible effects in the analysis since these mild recessions are usually very short lived. On the contrary, if our interest is on length, depth or shape, the effects of including mild recessions will only be averaged out from large sets of complete cycles, which should come from very large time series.

However, these large time series are usually not available in empirical work. If this is the case, including a mild recession in the middle of an expansion will lead to important changes in the description of the business cycle characteristics. The problem is aggravated by using standard dating methods since they typically lose a valuable amount of information in the tails of the time series as they are not able to locate the first and last turning points. All of these problems are embedded in the analyses that include time series of the recently acceded countries, which rarely contain more than two or three complete cycles.

For all of these reasons, the studies of business cycle characteristics have been very dependent on the particular dating method used in these analyses. This dependence and the associated lack

\footnotetext{
${ }^{5}$ For a comprehensive coverage on parametric techniques in business cycle identification, we refer interested readers to Camacho and Perez-Quiros (2002).

${ }^{6}$ Nonparametric models have been criticized for using ad-hoc dating rules. Parametric models have the inconvenience of making all the business cycle analysis to rely on the underlying model's assumptions.

${ }^{7}$ See Camacho, Perez-Quiros and Saiz (2005) for an extensive discussion about this point.
} 
of robustness of the results have probably been the main drawback that had diminished the impact of the papers that analyze the similarities of the business cycle besides synchronization.

\subsection{Stationary bootstrap analysis}

To overcome the previous drawbacks, a reasonable solution may be found in bootstrapping the original series. In our case, the bootstrap procedure should be based on moving blocks bootstraps since they involve resampling methods to form pseudo-time series that retain the autocorrelation structure of the original data. Among the several methods developed for time series, we use the stationary bootstrap resampling scheme of Politis and Romano (1994) since this method is relatively less sensitive to the choice of the block length than other standard moving blocks bootstrap methods. ${ }^{8}$

The implementation of this method consists on bootstrapping blocks of the original data in which the first observation in each block is sampled from a discrete uniform distribution on $\{1, \ldots, T\}$, where $T$ is the sample size. The block length, $l$, is randomly sampled from a geometric distribution, whose density function is

$$
P(l=k)=(1-p) p^{k-1},
$$

for $k=1,2, \ldots$, and some $p \in[0,1]$, that refers to the probability of incorporating one observation to the block. In this case, the expected size of each block is then given by

$$
E(l)=(1-p)^{-1}
$$

In short, the proposed way of using stationary bootstrap to compute the business cycle characteristics consists on generating 10,000 bootstrapped time series from the original data. Each of these series comes from a concatenation of blocks of random size $l$.

Having the bootstrapped time series, we apply the Bry-Boschan algorithm to compute their respective 10,000 business cycle turning points chronologies. ${ }^{9}$ Each of them serves the basis for calculating one point estimate of the empirical distribution of the business cycle features that we have previously selected to describe the business cycle. Final business cycle characteristics are computed by averaging from their empirical distributions.

This method mitigates the problem of the dating of recessions with short time series with just a few full cycles observed. From the bootstrapped series, we generate thousands of full cycles

\footnotetext{
${ }^{8}$ These authors show that the stationary bootstrap method leads to consistency and weak convergence of the resampling.

${ }^{9}$ Among the nonparametric dating methods, we select the Bry-Boschan algorithm since it is the easiest way to search turning points in our large set of replications.
} 
for which we can estimate the proposed business cycle characteristics and their standard errors. Additionally, we solve the problem of the effect of mild business cycle phases. The reason is that, although the dating algorithm may produce atypical characteristics due to the existence of mild business cycle phases, they are expected to be averaged out by bootstrapping if they are not part of the data generating process. In addition, the valuable information that is associated to the beginning and to the end of the time series will be included in the stationary bootstrap analysis.

Let us examine with an illustrative example the validity of the stationary bootstrap method in the analysis of business cycles characteristics. To start with, we generate ten different time series of 200 observations from the same data generating process that is supposed to follow a Markov switching process as in Hamilton (1989). In order to provide the data generating process with economic meaning, we impose the generated data to have similar expected business cycle properties to those that we observe the data. For this purpose, we first apply the Bry-Boschan algorithm to our sample of countries and compute the within expansions and within recessions averaged values of duration (41 and 17 months), amplitude (15\% and $-12 \%$ ), means (0.005 and $-0.007)$, and standard deviation (0.001). According to the figures for duration, the probabilities of staying in expansions and recessions are 0.976 and 0.940 , respectively. Finally, we simplify the experiment by considering that the data generating process is linear in both phases of the cycle which leads to measures of excess equal to zero. The expected business cycle characteristics of these generated series are presented in the first row of Table 1.

We first proceed to date the turning points of the ten generated series by means of the BryBoschan algorithm and then, to obtain duration, amplitude and excess of the identified recessions and expansions. The resulting business cycle characteristics are shown at the top of Table 1 . Although the ten time series have been generated from the same data generating process, there are considerable differences among their business cycle characteristics. The ranges of variation of these characteristics are usually larger than twice their expected values, leading in some cases to business cycle characteristics that clearly misrepresent the actual characteristics of the data generating process. For example, in the fifth generated series expansions are much longer, deeper and sharper, and recessions are much shorter and smoother than in the rest of the generated samples and than in the data generating process. This example illustrates that the high degree of uncertainty associated to some turning points obtained with dating algorithms may lead the results on business cycle characteristics to be highly imprecise.

Let us now move to the stationary bootstrap results. For each of the ten generated samples, we compute 10,000 bootstrapped time series by resampling blocks of expected length of 41 months 
( $p=0.976)$ since this is the mean duration of expansions in our sample of countries. ${ }^{10}$ The resulting averaged business cycle characteristics are displayed at the bottom of Table 1. The dispersion of the business cycle characteristics has dramatically reduced, and the averaged values for all the ten generated series are much closer to their expected values than in the case of computing these characteristics with the standard method. It is worth noting that the bootstrapped characteristics sometimes coincide with their expected values. These results confirm the usefulness of the stationary bootstrap method to compute robust business cycles characteristics. ${ }^{11}$

\subsection{Grouping countries with similar characteristics}

In order to provide a complete framework to analyze business cycle characteristics, it is useful to consider a principled statistical approach that allows us to summarize results. For this purpose, we adopt the mixture models clustering approach described by Fraley and Raftery (2002). Using this method we can group countries with similar characteristics, and test whether these countries exhibit business cycle characteristics similar enough to consider one cycle with similar characteristics for all of them.

To outline the strategy of clustering based on mixture models, let us consider that the population of interest may consist of $G$ different subpopulations. Given a sample of $N$ countries, let us collect the $d$ business cycle characteristics of any country $n$ in the $d$-dimensional vector $x_{n}{ }^{12}$ Assume that each observation is a sample drawn from a probability distribution with joint density:

$$
f\left(x \mid \tau_{g}, \mu_{g}, \Sigma_{g}\right)=\sum_{g=1}^{G} \tau_{g} \Phi\left(x \mid \mu_{g}, \Sigma_{g}\right),
$$

where the $\tau_{g}$ 's are the mixing proportions, with $\tau_{g} \geqslant 0$, and $\sum_{g=1}^{G} \tau_{g}=1$, and $\Phi\left(x \mid \mu_{g}, \Sigma_{g}\right)$ is the $p$-dimensional Gaussian density, with $\mu_{g}$ and $\Sigma_{g}$ being its mean vector and covariance matrix, respectively. The goal of the mixture maximum likelihood method is to find the parameters $\tau_{g} \mu_{g}$, and $\Sigma_{g}$, collected in $\tau, \mu$, and $\Sigma$, that maximize the likelihood:

$$
L(\tau, \mu, \Sigma)=\prod_{n=1}^{N} f\left(x_{n} \mid \tau_{g}, \mu_{g}, \Sigma_{g}\right) .
$$

\footnotetext{
${ }^{10}$ In the empirical analysis, we show that our results are robust to reasonable values of the expected block sizes.

${ }^{11}$ We acknowledge that, since our method keeps the autocorrelation structure of the original data, it may be influenced by historically exceptional events affecting short time series. If the data generating process changes over time, the results may depend on the sample period chosen although they will still be robust to the dating method employed in the analysis.

${ }^{12}$ In our case, we consider six business cycle characteristics that correspond to duration, amplitude and excess for expansions and recessions, respectively.
} 
As the authors describe, the parameter estimates may be found through the expectation-maximization (EM) algorithm, that is a general approach to maximum likelihood in the presence of incomplete data. This algorithm initializes with an initial guess of $z_{n g}$, the posterior probabilities that country $n$ belongs to cluster $g$, given the maximum likelihood estimates $\tau, \mu$, and $\Sigma$. On the one hand, the M-step, consists on estimating the mixing proportions and means from the simple closed forms,

$$
\tau_{g}=\frac{n_{g}}{N}, \text { and } \mu_{g}=\frac{1}{n_{g}} \sum_{n=1}^{N} z_{n g} x_{n}
$$

with $n_{g}=\sum_{n=1}^{N} z_{n g}$. These authors show that the geometric properties (volume, shape and orientation) are governed by the covariances $\Sigma_{g}$. In particular, they propose a parametrization of the variances in terms of its eigenvalue decomposition:

$$
\Sigma_{g}=\lambda_{g} D_{g} A_{g} D_{g}^{\prime}
$$

The parameter $\lambda_{g}$ governs the volume of the cluster. The matrix $A_{g}$ is a diagonal matrix such that $\left|A_{g}\right|=1$, with the normalized eigenvalues of $\Sigma_{g}$ on the in decreasing order, and determines its shape. Finally, the matrix $D_{g}$ is formed by the eigenvectors of $\Sigma_{g}$ and determines its orientation. Due to the reduced number of sample observations, in this paper we assume that the clusters are spherical but have different volumes, that is $\Sigma_{g}=\lambda_{g} I$, where

$$
\lambda_{g}=\frac{1}{p n_{g}} \operatorname{tr}\left(W_{g}\right), \text { with } W_{g}=\sum_{n=1}^{N} z_{n g}\left(x_{n}-\mu_{g}\right)\left(x_{n}-\mu_{g}\right)^{\prime} .
$$

In this respect, it is worth pointing out that Celeux and Govaert (1995) apply Monte Carlo simulations to show that this parsimonious version is capable of detecting many clustering structures even for small data sets. On the other hand, the E-step consists on computing the estimated posterior probabilities as follows:

$$
z_{n g}=\frac{\tau_{g} \Phi\left(x \mid \mu_{n g}, \Sigma_{g}\right)}{\sum_{g=1}^{G} \tau_{g} \Phi\left(x \mid \mu_{n g}, \Sigma_{g}\right)} .
$$

The EM algorithm is iterated until the relative difference between successive values of the likelihood falls below a small threshold. Finally, we assign country $n$ to cluster $g$ whenever the posterior probability that this country belongs to cluster $g$ is maximum over the $G$ existing clusters.

The mixture models clustering approach allows us to examine whether the EU countries exhibit similar business cycle features. If these countries show business cycle features that were similar enough to consider a common business cycle pattern then only one cluster should be enough to characterize their business cycle characteristics. On the contrary, two or more clusters would indicate the existence of separate clusters with differentiated business cycle characteristics. Hence, 
the question of examining the similarities among the countries business cycle features may be reduced to compare two models, $M_{i}$ and $M_{j}$, with $i$ and $j$ clusters, respectively.

It is worth noting that standard likelihood ratio tests cannot be applied in this context due to the presence of nuisance parameters. Fraley and Raftery (2002) base the decision of $M_{i}$ versus $M_{j}$ on the model that is more likely a posteriori. Given the set of available data $D$, they define the Bayes factor as the ratio of the two integrated likelihoods, that is $B_{j i}=p\left(D \mid M_{j}\right) / p\left(D \mid M_{i}\right)$ and use the results of Kass and Raftery (1995) to propose that values $2 \ln \left(B_{j i}\right)$ less than 2 correspond to weak evidence in favor of $M_{j}$, values between 2 and 6 to positive evidence, between 6 and 10 to strong evidence, and greater than 10 to very strong evidence. Finally, Roeder and Wasseman (1997) develop simulation experiments to show that, when the EM algorithm is used to find the maximum likelihood, a reliable rough equivalent to $2 \ln (p(D \mid M))$ is the Bayesian information criterion (BIC). And thus, this permits approximate $2 \ln \left(B_{j i}\right)$ through the difference between their respective BICs:

$$
2 \ln \left(B_{j i}\right)=2 \ln \left(p\left(D / M_{j}\right)\right)-2 \ln \left(p\left(D / M_{i}\right)\right) \approx B I C_{j}-B I C_{i} .
$$

\section{Empirical results}

\subsection{Data description}

In this paper, we consider a sample of countries which covers the European countries that belonged to the Union prior to its recent enlargement: Belgium (BG), Denmark (DK), France (FR), Germany (BD), Greece (GR), Ireland (IR), Italy (IT), Luxembourg (LX), Netherlands (NL), Portugal (PT), Spain (ES), United Kingdom (UK), Austria (OE), Finland (FN) and Sweden (SD). In addition, with the exception of Malta for which the data were unavailable, we include the new members: Cyprus (CY), Estonia (ET), Latvia (LA), Lithuania (LI), Poland (PO), Slovakia (SK), Slovenia (SL), the Czech Republic (CZ), Hungary (HN), and Romania (RO). Finally, Turkey (TK) and four industrialized economies, Canada (CN), Japan (JP), Norway (NW) and the United States (US), have been taken as reference.

The first best on business cycle studies consists on identifying business cycles on the basis of measures of aggregate economic activity. ${ }^{13}$ However, due to data availability problems, we concen-

\footnotetext{
${ }^{13}$ In early versions of this paper, this motivated us to construct economic diffusion indexes following the lines of Stock and Watson (2002). However, owing to the lack of data availability that characterizes some of the EU new members, we had to give up after obtaining some misleading preliminary results. Additionally, we developed experimental indexes of coincident indicators by averaging series of industrial production, personal income, sales, and employment, as proposed by Stock and Watson (1989). However, the Kalman filter used to compute the indexes assigned negligible weights to time series other than industrial production in many countries.
} 
trate on the analysis of the (seasonally adjusted) Industrial Production (IP) index extracted from the OECD Main Economic Indicators and the IMF international Financial Statistics Databases. As documented by Artis et al. (2005), in contrast to Gross Domestic Product (GDP) series, the IP series are available monthly, are more homogeneous across countries, and usually cover longer samples. In addition, for many economies, GDP is not based on quarterly national accounts but it is annual and converted to quarterly by using indicators. Finally, our time series span from 1962.01 to 2004.03. However, due to data constraints, we start the sample in 1990.01 in those exercises that include the recently acceded countries. ${ }^{14}$ The number of countries and the length of the samples used in this paper allow this study to complement the business cycle studies that have been mainly focused on synchronization, including our own work, Camacho et al. (2006).

\subsection{EU business cycle characteristics}

Prior to analyzing the EU business cycle characteristics, we examine the potential dependence of the stationary bootstrap method to the selected block length. For robustness checking, we apply the bootstraps to expected block sizes of 19,32 and 66 months and the results are displayed in Tables A1 to A3 of the Appendix. ${ }^{15}$ In spite of the different expected block sizes used in the computations, these tables report that the business cycle characteristics are very similar for all countries (on average, they are roughly coincident). This robustness check confirms that our results will no longer be affected by resampling with blocks of reasonable expected lengths.

Let us then concentrate on the business cycle analysis that uses bootstraps with blocks of expected size of 32 months since this is the mode of the average duration of expansions in our sample of countries. For this purpose, Table 2 reports the median values (from 10, 000 replications) of the six business cycle characteristics that have been obtained for our set of thirty countries. Let us summarize the results as follows.

Business cycle duration. The median duration of expansions is about 31 months meanwhile it is just about 15 months in the case of recessions. Thus, according to a broadly accepted stylized fact in the business cycle literature, expansions appear to be much longer than recessions. Of noticeable interest is the particularly strong asymmetric duration between the two phases of the cycle exhibited by Ireland, Hungary and Poland for which the percentage of time spent in expansions is roughly four times of that in recessions. On the other hand, it is worth noting that expansions have been considerably short lived in some of the countries that have recently joined the Union as Lithuania,

\footnotetext{
${ }^{14}$ Following Blanchard (2003), we elude atypical downturns by not using the first two years of observations of Latvia, Czech Republic, Hungary, Poland and Slovenia.

${ }^{15}$ We checked that mean and median values lead to similar results.
} 
Latvia and Cyprus. Finally, we obtain that recessions have also been short in the set of non European countries included in the analysis as reference.

Business cycle amplitude. Again, we observe evidence of asymmetries across the phases of the cycle. Expansions are generally wider than recessions which leads the gain in terms of production in expansions (about 18\%) to be considerably higher than the loss suffered from the decline of contractions (about 11\%). The case of Ireland is remarkable for the extreme gains obtained during the expansive phase. Once more, Hungary, and to less extent, Poland stand out for their pronounced business cycle asymmetries. Finally, it is worth noting that Eastern countries show wider and more severe recessions than other European countries.

Business cycle excess. On average, expansions are convex since the excess is positive (about 0.12). This means that expansions start with smooth growth rates of industrial production and end with steep ones. However, falls in production tend to be roughly linear during the recessive phase since the excess is about zero. In terms of the shape of the cycle, the countries with highest gains in expansions exhibit positive excess, with convex expansion periods. However, there is no a clear pattern between recession shapes and other recession features.

Finally, we conclude the section with an analysis of the evolution over time of the business cycle characteristics. For this purpose, Table 3 reports the business cycle characteristics for two nonoverlapping subperiods: 1962.01-1989.12 and 1990.01-2004.03. ${ }^{16}$ Comparing the two subperiods, the degree of business cycle asymmetries decreases on average. In line with the literature on the recent volatility decline (see McConnell and Perez-Quiros, 2000), cycles become smoother due to the reduction in the amplitude of both phases of the cycle. On the other hand, expansions turned into convex for most countries since the excess switches from negative to positive. This result goes in line with Kim and Murray (2002), who find that the existence the of the recovery phase of rapid growth detected by Sichel (1994) is no longer present in the last expansions.

\subsection{Is there just one cluster of European business cycles?}

As stated in the previous section, there are business cycle characteristics that appear to be shared by the major European economies. However, it also points out that some of them widely differ from one country to another. A telling example comes from the comparison of Ireland and UK. While both countries exhibit similar excess in recessions (0.07), the amplitude of expansions is much higher in Ireland (45\%) than in UK $(6 \%)$. In this section, we investigate the degree of heterogeneity across the EU countries' business cycle characteristics.

The first question that we address is to examine whether these countries exhibit business cycle

\footnotetext{
${ }^{16}$ Owing to data availability, we exclude the new EU members from this last analysis.
} 
features that were similar enough to consider that there are differentiated European business cycle characteristics. On the basis of the mixture clustering approach, the analysis may be reduced to compare the likelihoods of forming just one cluster of countries with the alternative scenario of two (or more) clusters. To deal with this question, Table 4 shows the BICs and the estimated clusters for several models from $M_{1}$, which considers only one cluster, to $M_{5}$, which considers five clusters. ${ }^{17}$ Comparing the model with one cluster with the model with two clusters, the transformation of the Bayes factor, $2 \ln \left(B_{21}\right)$, is 6.7 that is higher than 6 . This supports the conclusion that, attending to the business cycle characteristics, there is strong empirical evidence against null of one European cycle.

The next stage is to determine the optimal number of clusters. According to Table 4, the four-cluster model reaches the maximum BIC value. The difference in the BICs between the threecluster and the four-cluster models is 6.07 which is high enough to validate that there may be four clusters of countries with cohesive and separate business cycle characteristics. These clusters and their business cycle characteristics are reported in Table 5 .

The first cluster is formed by Turkey and some EU-enlargement countries, Cyprus, Estonia, Latvia, Lithuania and Romania. The main characteristics of this cluster are the short duration of their expansions (with the exception of Turkey) and the high amplitude of their recessions. On average, their expansions last just about 27 months whereas their recessions last about 17 months. In addition, the amplitude of their expansions and recessions is similar (about 0.20 in absolute value). This leads their recessions to be severe and to destroy the gains of expansions.

The second cluster includes United States, Canada, some Nordic countries and two EU-enlargement countries, Slovakia and the Czech Republic. Their cycles are characterized by short and smooth recessions, and by convex expansions. In particular, they have expansions of about 34 months and recessions of about 14 months. The amplitude of their expansions is, in absolute value, twice the amplitude of their recessions. The positive excess exhibited in their last expansions reveals that growth is smooth at the beginning and abrupt at the end of the expansive phase. Hence, this cluster is characterized by long and deep, expansions in relation to recessions.

The third cluster, which contains the majority of EU-15 countries, is formed by economies with low amplitude of both expansions and recessions. These countries present a mean duration of expansions and recessions of about 28 and 18 months, respectively. In absolute value, the amplitude of expansions is slightly higher than the amplitude of recessions, but in general, both are very mild.

\footnotetext{
${ }^{17}$ The estimation of models with more than five clusters is worthless since there would not be enough observations to calculate all the model's parameters.
} 
The last cluster incorporates those countries that exhibit the most atypical business cycle characteristics: Ireland, Hungary and Poland. Their expansions are very long, wide, and convex, and their recessions very short. On average, their expansive phases last about 44 months whereas contractions last just about 9 months. In these countries, expansions exhibit an amplitude whose magnitude is more than three times the amplitude of recessions, so they are relatively very convex. Accordingly, these countries have obtained in the last years extreme positive benefits from expansions that have not been lost in recessions.

The analysis of the EMU countries and its location among clusters deserves especial attemption. It is important to point out that the EMU countries are situated in different clusters and that only in the first cluster there are no EMU countries. To be more exhaustive, in a previous version of the paper (see Camacho, Perez-Quiros and Saiz, 2005) we repeat the exercise just for the EU countries obtaining the same results. ${ }^{18}$ This result highlights that the business cycles of not only EU but EMU countries are still substantially different according to their duration, deepness and shape. As suggested by the survey of Haan et al. (2007), this goes in line with the findings in business cycle synchronization.

Following recent contributions in synchronization we take up now the issue of whether there is a trend to reduce the differences in the characteristics of the EMU business cycles. ${ }^{19}$ Since we do not have a single measure of business cycle dissimilarities as the studies of synchronization have, we ask if the distribution of business cycle characteristics across the EMU countries is becoming more similar, i.e. if the dispersion in their business cycle characteristics falls over time. For this purpose, we break the sample into two subsamples, with the cutoff being the beginning of the nineties, and compute the coefficient of variations for duration and amplitude and the standard deviation for excess (the coefficient of variation is not well behaved for means close to zero). As Table 6 shows, the coefficients of variation and the standard deviations do not diminish over time. In fact, for most of the business cycle characteristics they increase in the second subsample suggesting that the differences in business cycle characteristics have increased rather than reduced. As Inklaar and de Haan (2001) suggest, the increase in exchange rate stability had not implied convergence in the synchronization of the European countries. It seems that it have not implied convergence in other business cycle characteristics either.

\footnotetext{
${ }^{18}$ As suggested by one of the referees, we also repeat the exercise by including just the EMU countries. Imposing three clusters the EMU countries are distributed among them as in the whole-sample case. However, we can not reject the null of just one group, mainly because the lack of power in the test.

${ }^{19}$ The sign of this trend is not clear in the analysis of synchronization. See the illustrative example of the discussion between Artis and Zhang (1999) and Inklaar and de Haan (2001).
} 


\subsection{Synchronization vs similarities of characteristics}

Coming back to the issues that motivate this paper, we think the literature on business cycles is devoting a disproportionate attention to business cycle synchronization in contrast to other characteristics that describe the form of the business cycle. This would not become a source of debate if countries exhibiting more synchronized cycles showed more similar business cycle characteristics. However, we have serious doubts that this actually was the case in practice. In this respect, it is worth examining the strength of the potential relation between the results on business cycle characteristics of this paper with previous findings on synchronization. In order to build this relation, we use the results of Camacho et al. (2006), since we use the same cluster of countries and similar samples of industrial production series.

In that paper we computed measures of pairwise distances in business cycle synchronization. Our purpose is now to compare them with measures of pairwise distances in business cycle characteristics. For this attempt, we deal with a simple measure of dissimilarity by computing the Euclidean distance in business cycle characteristics between each pair of countries. That is, letting $x_{i j}$ denote the $i$-th characteristic of country $j$, the distance on business cycle characteristics between countries $A$ and $B$ is:

$$
d_{A, B}=\sqrt{\sum_{i=1}^{d}\left(x_{i, A}-x_{i, B}\right)^{2}},
$$

where $d$ is the total number of business cycle characteristics.

Note that, from this exercise we obtain a set of obtain 435 different distances. In order to facilitate a visual inspection of these distances, we follow Camacho et al. (2006) to give the multidimensional scaling map depicted in Figure 2. This map is a two-dimensional projection that approximates on a plane the distances across countries in terms of their business cycle dissimilarities. That is, countries with dissimilar business cycle characteristics are located in the map relatively far way from each other. For example, according to our previous findings, Ireland Hungary and Poland are points far apart in the map which reflects that they exhibit the most atypical business cycle characteristics. However, other EU countries seem to have more similar characteristics since they are represented by points that are more close together.

The correlation coefficient between the distances in business cycle synchronization and the Euclidean distances in business cycle characteristics is 0.32 (standard deviation of 0.05). As expected, it is positive and statistically significant suggesting that there is some relation between synchronization, duration, amplitude and excess. However, it is also significantly lower than one, the value that is associated with perfect correlation. Hence, the distances from these two measures share some characteristics but they preserve independent movements. 
To further study if synchronization and characteristics imply the same clustering, we compute a contingency table from the results obtained by using these two approaches. First, we apply the $k$-medoid method to impose four clusters in the analysis of distances in synchronization. ${ }^{20}$ Second, for the 435 pairwise relations from the analyses of both synchronization and characteristic, we define two binary variables that take value 1 if the two countries belong to the same group and 0 otherwise. Finally, we summarize the results in the contingency table presented in Table 7. Cells in the main diagonal represent the concordance of distances in synchronization and in characteristics while cells out of the main diagonal represent the degree of dissimilarities. That is to say, out of the 435 pairwise distances, both criteria lead to similar results in 263 cases (39 times refer to pairs of countries that belong to the same cluster and 224 times they refer to different clusters) while they lead to conflicting results in 172 cases.

In order to formally asses the degree of concordance between the two clustering exercises, we compute the Kappa index introduced by Cohen (1960). For this purpose, let $a_{i j}$ be the cell $(i, j)$ in the contingency table, with $i, j=1,2$. Let $a_{i \bullet}$ and $a_{\bullet j}$ be their respective marginal sums, and let $a_{\bullet \bullet}$ be the total number of observations. Let $P_{0}$ be the observational probability of agreement, $\left(a_{11}+a_{22}\right) / a_{\bullet \bullet}$, and $P_{e}$ be the expected probability of agreement under the null of independence, $\left(a_{\bullet 1} a_{1} \bullet+a_{\bullet 2} a_{2} \bullet\right) / a_{\bullet \bullet}^{2}$. The Kappa index is defined as the extent to which the observational probability of agreement is in excess of the probability of agreement expected under independence,

$$
\kappa=\frac{P_{0}-P_{e}}{1-P_{e}}
$$

Thus, the index has a range from $-P_{e} /\left(1-P_{e}\right)$ to 1 , with larger values indicating better reliability. In our case, the index is very low, 0.04 , with a $p$-value of the null hypothesis of independence between the two criteria of 0.45 which reveals little agreement between synchronization and characteristics in the clustering analysis. The rejection of this test reinforces the result that there is independent information content in the analysis of characteristics that is not reflected in the analysis of synchronization.

Finally, we regress distances in characteristics on distances in synchronization and on the set of macroeconomic variables selected in Camacho et al. (2006). Skipping details that can be found in that paper, these variables include trade linkages, and differences in industrial sector, agricultural sector, public balance, saving ratio, and labor productivity. After controlling for potential endogeneity, distances in synchronization are significant ( $t$ statistic of 3.15) in this regression but they only explain about $2 \%$ of the variance of the distances in characteristics. This result supports

\footnotetext{
${ }^{20}$ In the case of synchronization, we can not use Fraley and Raftery (2002) because we only have pairwise distances across countries.
} 
the fact that having synchronized cycles is a necessary but not sufficient condition for countries to exhibit similar business cycles. Again, we obtain that features that are key to describe the business cycles as duration, amplitude and shape, are only partially related to synchronization.

\section{Conclusions}

In this paper, we provide a comprehensive framework for comparing business cycle characteristics across a large set of countries with potential problems of data availability. First, we examine the minimum set of characteristics needed for a complete description of the cycle. Second, we show how stationary bootstrap methods may be used to obtain robust business cycle characteristics from time series. Our proposal minimizes typical problems of other studies on business cycles, such as the dependence of the results on the existence of mild business cycle phases, the low number of complete cycles and the presence of incomplete cycles. Finally, we adopt a statistical method from other scientific disciplines, the model based clustering approach, that allows us to form clusters from countries with the similar business cycle characteristics.

We apply these methods to analyze similarities and differences among the EU countries (and some others that are used as reference). We find evidence against the existence of just one European cycle whose length, deep and shape might be representative of the whole EU or the EMU area. Reinforcing the results in synchronization surveyed by de Haan et al. (2007), this finding emphasizes the difficulty of choosing an appropriate monetary policy stance given the actual differences in business cycle features.

We also analyze the evolution of the business cycle characteristics over time by breaking the sample into two subsamples, with the cutoff being the beginning of the nineties. Our results are in line with the results on synchronization obtained by Inklaar and de Haan (2001). It seems that an increase in exchange rate stability has not implied convergence in business cycle characteristics.

Finally, we investigate the degree of concordance between the results on synchronization and those on business cycle characteristics. Our results suggest that, although there is some relation between distances in business cycle synchronization and distances in business cycle characteristics, there is independent information in the analysis of characteristics that is not reflected in the analysis of synchronization. This latest result calls the attention to the disproportionate interest that has been devoted to synchronization relative to other business cycle characteristics. 


\section{References}

[1] Artis, M., and Zhang, W. 1999. Further evidence on the international business cycles and the ERM: Is there a European business cycle? Oxford Economic Papers 51: 120-132.

[2] Artis, M., Marcellino, M. and Proietti, T. 2004. Dating business cycles: a methodological contribution with an application to the Euro area. Oxford Bulletin of Economics and Statistics 6: $537-565$.

[3] Artis, M., Marcellino, M. and Proietti, T. 2005. Business Cycles in the new EU member countries and their conformity with the Euro area. Journal of Business Cycle Measurement and Analysis 2: 7-41.

[4] Blanchard, O. 2003. Macroeconomics. Upper Saddle River, New Jersey: Prentice Hall.

[5] Bry, G., and Boschan, C. 1979. Cyclical analysis of time series: selected procedures and computer program. Columbia University Press: New York.

[6] Camacho, M., and Perez-Quiros, G. 2002. This is what the leading indicators lead. Journal of Applied Econometrics 17: 61-80.

[7] Camacho, M., and Perez-Quiros, G. and Saiz, L. 2006. Are European business cycles close enough to be just one? Journal of Economic Dynamics and Control, 30, 1687-1706.

[8] Camacho, M., and Perez-Quiros, G. and Saiz, L. 2005. Do European business cycles look like one? Bank of Spain Working Paper No. 0518.

[9] Celeux, G., and Govaert G. 1995. Gaussian parsimonious clustering methods. Pattern Recognition 28: 781-793.

[10] Cohen, J. 1960. A coefficient of agreement for nominal scales. Educational and Psychological Measurement 20: 37-46.

[11] De Haan, J., Inklaar, R., and Jong-A-Pin, R. 2007. Will business cycle in the Euro area converge? A critical survey of empirica research. Journal of Economic Surveys, forthcoming.

[12] Darvas, Z., and Szapary, G. 2005. Business cycle synchronization in the enlarged EU. CEPR Discussion Paper No. 5179.

[13] Dueker, M., and Wesche, K. 2003. European business cycles: New indices and analysis of their synchronicity. Economic Inquiry 41: 116-131. 
[14] Fraley, C., and Raftery, E. 2002. Model based clustering, discriminant analysis and density estimation. Journal of American Statistical Association 97: 611-631.

[15] Hamilton, J. 1989. A new approach to the economic analysis of nonstationary time series and the business cycles. Econometrica 57, 357-384.

[16] Harding, D., and Pagan, A. 2002a. Dissecting the cycle: a methodological investigation. Journal of Monetary Economics 49: 365-381.

[17] Harding, D., and Pagan, A. 2002b. A comparison of two business cycle dating methods. Journal of Economic Dynamics and Control 27: 1681-1690.

[18] Inklaar, R., and de Haan, J. 2001. Is there really a European business cycle? A comment. Oxford Economic Papers 53, 215-220

[19] Kass R., and Raftery, E. 1995. Bayes factors. Journal of the American Statistical Association 90: 773-795.

[20] Kim, C., and Murray, C. 2002. Permanent and transitory components of recessions. Empirical Economics 27: 163-183.

[21] Krozlig, H., and Toro, J. 2005. Classical and modern business cycle measurement: The European case. Spanish Economic Review 7: 1-22.

[22] McConnell, M., and Perez-Quiros, G. 2000. Output fluctuations in the United States: what has changed since the early 80s? American Economic Review 90: 1464-1476.

[23] Politis, D., and Romano, J. 1994. The stationary bootstrap. Journal of the American Statistical Association 89, 1303-1313.

[24] Roeder, K., and Wasseman, L. 1997. Practical Bayesian density estimation using mixtures of normals. Journal of the American Statistical Association 92, 894-902.

[25] Sichel, D. 1994. Inventories and the three phase of the business cycle. Journal of Business and Economic Statistics 12: 269-277.

[26] Stock, J., and Watson, M. 1989. New indexes of coincident and leading economic indicators. NBER Macroeconomics Annual: 351-409.

[27] Stock, J., and Watson, M. 2002 Macroeconomic forecasting using diffusion indexes. Journal of Business and Economic Statistics 20: 147-162. 
[28] Teräsvirta, T. 1994. Specification, estimation and evaluation of smooth transition autoregressive models. Journal of the American Statistical Association 89: 208-18.

[29] Trichet, J. 2001. The euro after two years. Journal of Common Markets Studies 39: 1-13.

[30] Tsay, R. 1989. Testing and modelling threshold autoregressive processes. Journal of American Statistical Association 84: 245-292. 
Table 1. Stationary bootstrap and business cycle characteristics.

\begin{tabular}{|c|c|c|c|c|c|c|c|c|}
\hline & & & \multicolumn{3}{|c|}{ EXPANSIONS } & \multicolumn{3}{|c|}{ RECESSIONS } \\
\hline & & & Duration & Amplitude & Excess & Duration & Amplitude & Excess \\
\hline \multicolumn{3}{|c|}{ Expected Value } & 41 & 0.15 & 0 & 17 & -0.12 & 0 \\
\hline \multirow{14}{*}{ 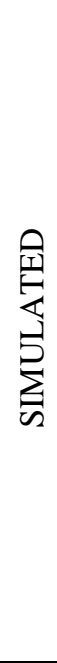 } & \multirow{10}{*}{ 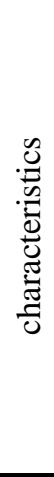 } & 1 & 30.25 & 0.15 & -0.18 & 19.75 & -0.13 & -0.11 \\
\hline & & 2 & 25.50 & 0.13 & -0.04 & 24.50 & -0.16 & 0.02 \\
\hline & & 3 & 37.67 & 0.16 & -0.46 & 43.50 & -0.29 & 0.09 \\
\hline & & 4 & 73.00 & 0.35 & -0.56 & 18.00 & -0.12 & -0.01 \\
\hline & & 5 & 95.50 & 0.45 & 2.21 & 9.00 & -0.07 & -0.01 \\
\hline & & 6 & 51.00 & 0.23 & 0.59 & 15.67 & -0.10 & -0.04 \\
\hline & & 7 & 45.67 & 0.23 & -0.08 & 31.50 & -0.20 & -0.43 \\
\hline & & 8 & 53.00 & 0.25 & 0.04 & 13.67 & -0.10 & -0.01 \\
\hline & & 9 & 52.50 & 0.26 & 0.04 & 31.67 & -0.21 & 0.00 \\
\hline & & 10 & 60.00 & 0.26 & -0.04 & 20.00 & -0.14 & -0.04 \\
\hline & \multirow{3}{*}{\multicolumn{2}{|c|}{$\begin{array}{c}\min \\
\text { max } \\
\text { Range }\end{array}$}} & 25.50 & 0.13 & -0.56 & 9.00 & -0.29 & -0.43 \\
\hline & & & 95.50 & 0.45 & 2.21 & 43.50 & -0.07 & 0.09 \\
\hline & & & 70.00 & 0.32 & 2.77 & 34.50 & 0.21 & 0.52 \\
\hline & \multicolumn{2}{|c|}{ Average } & 52.41 & 0.25 & 0.15 & 22.73 & -0.15 & -0.05 \\
\hline \multirow{14}{*}{ 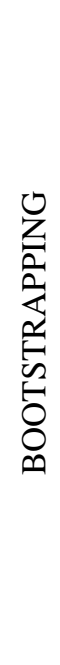 } & \multirow{10}{*}{ 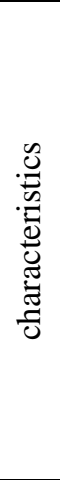 } & 1 & 31.43 & 0.15 & 0.02 & 17.35 & -0.12 & 0.01 \\
\hline & & 2 & 28.66 & 0.14 & -0.02 & 23.05 & -0.14 & -0.01 \\
\hline & & 3 & 30.70 & 0.14 & -0.04 & 31.66 & -0.20 & 0.02 \\
\hline & & 4 & 43.19 & 0.20 & -0.04 & 14.67 & -0.10 & 0.00 \\
\hline & & 5 & 57.93 & 0.28 & 0.00 & 8.92 & -0.07 & -0.01 \\
\hline & & 6 & 45.10 & 0.20 & 0.20 & 11.37 & -0.07 & -0.01 \\
\hline & & 7 & 37.95 & 0.18 & 0.02 & 24.64 & -0.15 & -0.17 \\
\hline & & 8 & 39.72 & 0.18 & 0.02 & 14.42 & -0.09 & -0.02 \\
\hline & & 9 & 35.48 & 0.17 & 0.02 & 26.21 & -0.18 & -0.05 \\
\hline & & 10 & 48.59 & 0.20 & 0.25 & 16.37 & -0.11 & -0.03 \\
\hline & \multirow{2}{*}{\multicolumn{2}{|c|}{$\begin{array}{l}\min \\
\operatorname{Max}\end{array}$}} & 28.66 & 0.14 & -0.04 & 8.92 & -0.20 & -0.17 \\
\hline & & & 57.93 & 0.28 & 0.25 & 31.66 & -0.07 & 0.02 \\
\hline & \multicolumn{2}{|c|}{ Range } & 29.27 & 0.14 & 0.29 & 22.74 & 0.13 & 0.20 \\
\hline & \multicolumn{2}{|c|}{ Average } & 39.87 & 0.18 & 0.04 & 18.86 & -0.12 & -0.03 \\
\hline
\end{tabular}

Notes. The simulated data correspond to 10 generated samples from the same data generating process of 200 observations. Based on applying Bry-Boschan to the sample of countries, the data generating process follows a Markov-switching model with two means, 0.005 for expansions and -0.007 for recessions, probabilities of staying in expansions and recessions of 0.976 and 0.940 , and standard deviation of 0.001 . The averaged characteristics are shown in the first row, labeled as expected values. Rows labeled as simulated refer to the characteristics of each of the 10 generated samples computed by using the Bry-Boschan method. Rows labeled as bootstrapping refer to the bootstrapped results that correspond to the average of the 10,000 bootstrap replications for each of these generated samples. 
Table 2. Business cycle characteristics from bootstrap method.

\begin{tabular}{|c|c|c|c|c|c|c|}
\hline \multirow{2}{*}{ Country } & \multicolumn{2}{|c|}{ Duration (months) } & \multicolumn{2}{|c|}{ Amplitude } & \multicolumn{2}{|c|}{ Excess } \\
\hline & Expansions & Recessions & Expansions & Recessions & Expansions & Recessions \\
\hline Austria & 35.50 & 13.00 & 0.18 & -0.06 & 0.15 & -0.02 \\
\hline Belgium & 28.00 & 18.75 & 0.12 & -0.08 & 0.03 & 0.04 \\
\hline Germany & 22.75 & 13.17 & 0.08 & -0.06 & 0.04 & -0.02 \\
\hline Greece & 30.33 & 23.67 & 0.12 & -0.09 & 0.31 & 0.08 \\
\hline Finland & 33.33 & 14.25 & 0.22 & -0.09 & 0.35 & -0.07 \\
\hline France & 30.67 & 18.50 & 0.08 & -0.04 & 0.04 & -0.05 \\
\hline Italy & 18.50 & 16.67 & 0.08 & -0.05 & -0.01 & -0.04 \\
\hline Luxemburg & 28.33 & 15.50 & 0.17 & -0.12 & 0.36 & -0.05 \\
\hline Netherlands & 31.33 & 17.67 & 0.10 & -0.07 & -0.18 & -0.12 \\
\hline Portugal & 28.00 & 22.00 & 0.14 & -0.12 & -0.28 & -0.17 \\
\hline Sweden & 36.00 & 15.67 & 0.18 & -0.08 & 0.45 & 0.04 \\
\hline UK & 36.00 & 21.00 & 0.06 & -0.05 & -0.01 & 0.07 \\
\hline Canada & 38.00 & 11.00 & 0.15 & -0.05 & 0.31 & 0.04 \\
\hline Norway & 25.00 & 17.60 & 0.13 & -0.09 & -0.07 & -0.08 \\
\hline Japan & 29.75 & 16.67 & 0.12 & -0.11 & 0.04 & 0.02 \\
\hline USA & 34.00 & 14.00 & 0.14 & -0.04 & 0.04 & -0.03 \\
\hline Spain & 32.25 & 14.25 & 0.12 & -0.07 & 0.11 & 0.00 \\
\hline Denmark & 29.00 & 15.00 & 0.17 & -0.11 & 0.13 & 0.01 \\
\hline Ireland & 47.33 & 10.67 & 0.45 & -0.16 & 0.44 & 0.07 \\
\hline Cyprus & 23.50 & 22.00 & 0.14 & -0.16 & 0.22 & 0.17 \\
\hline Czech & 33.67 & 12.50 & 0.17 & -0.10 & 0.08 & -0.09 \\
\hline Hungary & 43.67 & 8.00 & 0.33 & -0.07 & 1.03 & 0.03 \\
\hline Latvia & 21.00 & 16.67 & 0.18 & -0.21 & -0.04 & 0.20 \\
\hline Poland & 41.33 & 8.33 & 0.28 & -0.06 & 0.35 & -0.05 \\
\hline Slovenia & 27.67 & 16.33 & 0.15 & -0.11 & -0.21 & -0.04 \\
\hline Turkey & 34.33 & 17.00 & 0.24 & -0.20 & 0.08 & -0.21 \\
\hline Romania & 31.33 & 19.00 & 0.24 & -0.27 & -0.14 & 0.34 \\
\hline Slovakia & 36.33 & 11.00 & 0.21 & -0.09 & 0.18 & 0.05 \\
\hline Estonia & 29.00 & 11.00 & 0.27 & -0.18 & -0.33 & -0.15 \\
\hline Lithuania & 20.00 & 14.50 & 0.23 & -0.23 & 0.25 & 0.01 \\
\hline Average & 31.20 & 15.51 & 0.18 & -0.11 & 0.12 & 0.00 \\
\hline
\end{tabular}

Notes: The business cycle characteristics are calculated using the stationary bootstrap that has been described in Section 2 for $p=0.97$. The associated expected value of each block is 32 months. Results from bootstrapping with different block sizes are displayed in the Appendix. The results are medians from 10,000 replications. 
Table 3. Evolution of business cycle characteristics.

\begin{tabular}{|c|c|c|c|c|c|c|}
\hline \multirow{2}{*}{ Country } & \multicolumn{2}{|c|}{ Duration (months) } & \multicolumn{2}{|c|}{ Amplitude } & \multicolumn{2}{|c|}{ Excess } \\
\hline & Expansions & Recessions & Expansions & Recessions & Expansions & Recessions \\
\hline \multicolumn{7}{|c|}{ Sample:1962.1-1989.12 } \\
\hline Austria & 55.20 & 13.75 & 0.26 & -0.08 & 0.14 & 0.09 \\
\hline Belgium & 44.33 & 12.33 & 0.19 & -0.09 & 0.08 & 0.02 \\
\hline Germany & 46.00 & 17.20 & 0.20 & -0.09 & -0.44 & -0.12 \\
\hline Greece & 57.80 & 14.33 & 0.36 & -0.09 & -0.24 & -0.04 \\
\hline Finland & 57.80 & 12.60 & 0.34 & -0.15 & 0.01 & -0.20 \\
\hline France & 46.00 & 13.33 & 0.18 & -0.08 & 0.40 & 0.02 \\
\hline Italy & 49.80 & 14.17 & 0.27 & -0.13 & 0.26 & 0.05 \\
\hline Luxemburg & 28.29 & 16.56 & 0.24 & -0.21 & -0.20 & -0.11 \\
\hline Netherlands & 38.17 & 18.50 & 0.23 & -0.10 & -0.05 & 0.04 \\
\hline Portugal & 56.60 & 12.80 & 0.35 & -0.13 & -0.14 & -0.03 \\
\hline Sweden & 40.33 & 21.43 & 0.19 & -0.10 & 0.06 & 0.21 \\
\hline UK & 41.14 & 14.60 & 0.17 & -0.10 & -0.24 & -0.14 \\
\hline Canada & 38.43 & 14.00 & 0.22 & -0.08 & -0.27 & -0.06 \\
\hline Norway & 50.00 & 16.50 & 0.32 & -0.16 & -0.76 & 0.03 \\
\hline Japan & 58.40 & 12.00 & 0.41 & -0.09 & 0.06 & -0.07 \\
\hline USA & 49.60 & 15.33 & 0.22 & -0.08 & -0.54 & -0.14 \\
\hline Spain & 61.75 & 17.50 & 0.33 & -0.12 & 0.61 & -0.01 \\
\hline Denmark & 29.00 & 13.67 & 0.21 & -0.14 & -0.03 & -0.16 \\
\hline Ireland & 42.67 & 13.50 & 0.28 & -0.12 & 0.36 & -0.02 \\
\hline Average & 46.91 & 14.95 & 0.26 & -0.11 & -0.05 & -0.03 \\
\hline \multicolumn{7}{|c|}{ Sample: 1990.1-2004.3 } \\
\hline Austria & 35.50 & 13.00 & 0.18 & -0.06 & 0.15 & -0.02 \\
\hline Belgium & 28.00 & 18.75 & 0.12 & -0.08 & 0.03 & 0.04 \\
\hline Germany & 22.75 & 13.17 & 0.08 & -0.06 & 0.04 & -0.02 \\
\hline Greece & 30.33 & 23.67 & 0.12 & -0.09 & 0.31 & 0.08 \\
\hline Finland & 33.33 & 14.25 & 0.22 & -0.09 & 0.35 & -0.07 \\
\hline France & 30.67 & 18.50 & 0.08 & -0.04 & 0.04 & -0.05 \\
\hline Italy & 18.50 & 16.67 & 0.08 & -0.05 & -0.01 & -0.04 \\
\hline Luxemburg & 28.33 & 15.50 & 0.17 & -0.12 & 0.36 & -0.05 \\
\hline Netherlands & 31.33 & 17.67 & 0.10 & -0.07 & -0.18 & -0.12 \\
\hline Portugal & 28.00 & 22.00 & 0.14 & -0.12 & -0.28 & -0.17 \\
\hline Sweden & 36.00 & 15.67 & 0.18 & -0.08 & 0.45 & 0.04 \\
\hline UK & 36.00 & 21.00 & 0.06 & -0.05 & -0.01 & 0.07 \\
\hline Canada & 38.00 & 11.00 & 0.15 & -0.05 & 0.31 & 0.04 \\
\hline Norway & 25.00 & 17.60 & 0.13 & -0.09 & -0.07 & -0.08 \\
\hline Japan & 29.75 & 16.67 & 0.12 & -0.11 & 0.04 & 0.02 \\
\hline USA & 34.00 & 14.00 & 0.14 & -0.04 & 0.04 & -0.03 \\
\hline Spain & 32.25 & 14.25 & 0.12 & -0.07 & 0.11 & 0.00 \\
\hline Denmark & 29.00 & 15.00 & 0.17 & -0.11 & 0.13 & 0.01 \\
\hline Ireland & 47.33 & 10.67 & 0.45 & -0.16 & 0.44 & 0.07 \\
\hline Average & 31.27 & 16.26 & 0.15 & -0.08 & 0.12 & -0.01 \\
\hline
\end{tabular}

Notes: Business cycle characteristics based on the stationary bootstrap that has been described in Section 2 for different values samples. Figures are medians from 10,000 replications. 
Table 4. Determination of the number of clusters. All sample.

\begin{tabular}{ccc} 
Model & BIC & $2 \times \ln \left(B_{j i}\right)$ \\
\hline 1 cluster & -528.52 & -- \\
2 clusters & -521.83 & 6.70 \\
3 clusters & -517.80 & 4.03 \\
4 clusters & -511.72 & 6.07 \\
5 clusters & -513.79 & -2.07 \\
\hline
\end{tabular}

Notes. BIC refers to the Bayesian Information Criterion. $B_{j i}$ is the Bayes factor.

Table 5. Business cycle characteristics for each cluster. All sample.

\begin{tabular}{|c|c|c|c|c|c|c|c|}
\hline \multirow{2}{*}{\multicolumn{2}{|c|}{ Clusters }} & \multicolumn{3}{|c|}{ Expansions } & \multicolumn{3}{|c|}{ Recessions } \\
\hline & & Duration & Amplitude & Excess & Duration & Amplitude & Excess \\
\hline Cluster 1: & $\begin{array}{l}\text { CY, LA, } \\
\text { LI, ET, } \\
\text { TK, RO }\end{array}$ & 26.72 & 0.21 & 0.02 & 17.01 & -0.20 & 0.06 \\
\hline Cluster 2: & $\begin{array}{l}\text { OE, LX, } \\
\text { FN, SD, } \\
\text { DK, US, } \\
\text { ES, CN, } \\
\text { CZ, SK }\end{array}$ & 33.78 & 0.17 & 0.22 & 13.57 & -0.08 & -0.01 \\
\hline Cluster 3: & $\begin{array}{l}\text { BG, BD, } \\
\text { GR, FR, } \\
\text { IT, NL, } \\
\text { PT, UK, } \\
\text { NW, JP, } \\
\text { SL }\end{array}$ & 28.04 & 0.11 & -0.03 & 18.10 & -0.08 & -0.03 \\
\hline Cluster 4: & $\begin{array}{l}\text { IR, HN, } \\
\text { PO }\end{array}$ & 44.11 & 0.35 & 0.61 & 9.00 & -0.10 & 0.02 \\
\hline
\end{tabular}

Notes. Acronyms for these countries are specified in Section 3. 
Table 6. Trends in the EMU countries business cycle characteristics

\begin{tabular}{|c|c|c|c|c|c|c|}
\hline \multirow{2}{*}{ Period } & \multicolumn{2}{|c|}{ Duration } & \multicolumn{2}{c|}{ Amplitude } & \multicolumn{2}{c|}{ Excess } \\
\cline { 2 - 7 } & Expansions & Recessions & Expansions & Recessions & Expansions & Recessions \\
\hline $1962.1-1989.12$ & 0.2 & 0.1 & 0.2 & -0.3 & 0.3 & 0.1 \\
$1990.1-2004.3$ & 0.2 & 0.2 & 0.6 & -0.4 & 0.2 & 0.1 \\
\hline
\end{tabular}

Notes: Entries for duration and amplitude are coefficients of variation while entries for excess are standard deviations. They have been computed with figures from Table 3.

Table 7. Contingency table for pairwise distances classification

\begin{tabular}{|c|c|c|c|c|}
\hline \multicolumn{2}{|c|}{} & \multicolumn{2}{|c|}{ Business cycles characteristics } & \multirow{2}{*}{ Subtotal } \\
\cline { 3 - 4 } \multicolumn{2}{|c|}{ Synchronization } & Same cluster & Different cluster & 132 \\
\cline { 2 - 4 } & Same cluster & 39 & 93 & 303 \\
\cline { 2 - 4 } & Different cluster & 79 & 224 & 435 \\
\hline
\end{tabular}

Notes: Entries refer to the number of times that pairwise distances are computed for pairs of countries that are located either in the same or in different clusters under the alternative analyses of synchronization and characteristics. 
Table A1. Sensitivity analysis: duration.

\begin{tabular}{|l|c|c|c|c|c|c|}
\cline { 2 - 7 } \multicolumn{1}{c|}{} & \multicolumn{2}{c|}{$p=0.950$} & \multicolumn{2}{c|}{$p=0.970$} & \multicolumn{2}{c|}{$p=0.985$} \\
\multicolumn{1}{|c|}{ E[l]= 19} & \multicolumn{2}{c|}{$\mathrm{E}[\mathrm{l}]=32$} & \multicolumn{2}{c|}{$\mathrm{E}[]=66$} \\
\hline \multirow{2}{*}{ Country } & \multicolumn{2}{c|}{ Duration (months) } & \multicolumn{2}{c|}{ Duration (months) } & \multicolumn{2}{c|}{ Duration (months) } \\
\cline { 2 - 7 } & Expansions & Recessions & Expansions & Recessions & Expansions & Recessions \\
\hline Austria & 35.25 & 13.50 & 35.50 & 13.00 & 37.00 & 12.67 \\
Belgium & 27.25 & 18.75 & 28.00 & 18.75 & 28.00 & 18.60 \\
Germany & 24.50 & 14.60 & 22.75 & 13.17 & 21.80 & 12.00 \\
Greece & 28.00 & 22.00 & 30.33 & 23.67 & 32.33 & 25.25 \\
Finland & 33.75 & 14.00 & 33.33 & 14.25 & 32.50 & 14.33 \\
France & 29.00 & 18.25 & 30.67 & 18.50 & 32.50 & 18.75 \\
Italy & 19.40 & 17.25 & 18.50 & 16.67 & 17.50 & 16.00 \\
Luxemburg & 27.50 & 16.80 & 28.33 & 15.50 & 30.00 & 15.00 \\
Netherlands & 30.67 & 17.33 & 31.33 & 17.67 & 32.50 & 18.00 \\
Portugal & 27.33 & 21.75 & 28.00 & 22.00 & 30.50 & 21.75 \\
Sweden & 33.75 & 16.25 & 36.00 & 15.67 & 37.75 & 15.00 \\
UK & 34.67 & 19.00 & 36.00 & 21.00 & 36.33 & 24.33 \\
Canada & 37.75 & 11.33 & 38.00 & 11.00 & 40.33 & 11.00 \\
Norway & 26.25 & 17.50 & 25.00 & 17.60 & 23.80 & 18.20 \\
Japan & 27.75 & 17.25 & 29.75 & 16.67 & 30.50 & 16.00 \\
USA & 38.33 & 13.50 & 34.00 & 14.00 & 33.25 & 14.40 \\
Spain & 31.50 & 15.00 & 32.25 & 14.25 & 33.25 & 13.67 \\
Denmark & 29.00 & 14.75 & 29.00 & 15.00 & 28.67 & 17.33 \\
Ireland & 47.00 & 10.50 & 47.33 & 10.67 & 48.00 & 10.50 \\
Cyprus & 22.67 & 21.75 & 23.50 & 22.00 & 25.00 & 21.75 \\
Czech & 30.50 & 13.00 & 33.67 & 12.50 & 36.00 & 12.00 \\
Hungary & 43.33 & 8.00 & 43.67 & 8.00 & 43.67 & 8.00 \\
Latvia & 20.33 & 18.33 & 21.00 & 16.67 & 22.25 & 15.67 \\
Poland & 41.33 & 9.00 & 41.33 & 8.33 & 40.67 & 8.00 \\
Slovenia & 26.67 & 16.33 & 27.67 & 16.33 & 28.50 & 16.00 \\
Turkey & 32.75 & 17.60 & 34.33 & 17.00 & 35.33 & 17.33 \\
Romania & 30.33 & 18.00 & 31.33 & 19.00 & 32.67 & 19.00 \\
Slovakia & 34.67 & 11.00 & 36.33 & 11.00 & 37.33 & 11.00 \\
Estonia & 28.00 & 11.00 & 29.00 & 11.00 & 29.67 & 10.50 \\
Lithuania & 19.33 & 14.50 & 20.00 & 14.50 & 20.67 & 14.50 \\
\hline Average & 30.62 & 15.59 & 31.20 & 15.51 & 31.94 & 15.55 \\
\hline
\end{tabular}

Notes: Business cycle duration based on the stationary bootstrap that has been described in Section 2 for different values of $p$. Figures are medians from 10,000 replications. 
Table A2. Sensitivity analysis: amplitude.

\begin{tabular}{|c|c|c|c|c|c|c|}
\hline \multirow{3}{*}{ Country } & \multicolumn{2}{|c|}{$\begin{array}{c}p=0.950 \\
E[l]=19\end{array}$} & \multicolumn{2}{|c|}{$\begin{array}{c}p=0.970 \\
E[l]=32\end{array}$} & \multicolumn{2}{|c|}{$\begin{array}{c}p=0.985 \\
E[l]=66\end{array}$} \\
\hline & \multicolumn{2}{|c|}{ Amplitude } & \multicolumn{2}{|c|}{ Amplitude } & \multicolumn{2}{|c|}{ Amplitude } \\
\hline & Expansions & Recessions & Expansions & Recessions & Expansions & Recessions \\
\hline Austria & 0.18 & -0.07 & 0.18 & -0.06 & 0.19 & -0.06 \\
\hline Belgium & 0.12 & -0.09 & 0.12 & -0.08 & 0.12 & -0.07 \\
\hline Germany & 0.09 & -0.07 & 0.08 & -0.06 & 0.08 & -0.05 \\
\hline Greece & 0.12 & -0.09 & 0.12 & -0.09 & 0.12 & -0.09 \\
\hline Finland & 0.22 & -0.09 & 0.22 & -0.09 & 0.22 & -0.08 \\
\hline France & 0.08 & -0.04 & 0.08 & -0.04 & 0.09 & -0.04 \\
\hline Italy & 0.08 & -0.05 & 0.08 & -0.05 & 0.08 & -0.05 \\
\hline Luxemburg & 0.18 & -0.13 & 0.17 & -0.12 & 0.17 & -0.11 \\
\hline Netherlands & 0.10 & -0.08 & 0.10 & -0.07 & 0.10 & -0.07 \\
\hline Portugal & 0.14 & -0.12 & 0.14 & -0.12 & 0.15 & -0.12 \\
\hline Sweden & 0.17 & -0.08 & 0.18 & -0.08 & 0.18 & -0.07 \\
\hline UK & 0.06 & -0.05 & 0.06 & -0.05 & 0.06 & -0.05 \\
\hline Canada & 0.15 & -0.05 & 0.15 & -0.05 & 0.16 & -0.05 \\
\hline Norway & 0.14 & -0.10 & 0.13 & -0.09 & 0.12 & -0.09 \\
\hline Japan & 0.11 & -0.11 & 0.12 & -0.11 & 0.12 & -0.12 \\
\hline USA & 0.14 & -0.04 & 0.14 & -0.04 & 0.14 & -0.04 \\
\hline Spain & 0.13 & -0.07 & 0.12 & -0.07 & 0.13 & -0.07 \\
\hline Denmark & 0.17 & -0.11 & 0.17 & -0.11 & 0.17 & -0.10 \\
\hline Ireland & 0.45 & -0.17 & 0.45 & -0.16 & 0.45 & -0.17 \\
\hline Cyprus & 0.15 & -0.17 & 0.14 & -0.16 & 0.14 & -0.15 \\
\hline Czech & 0.16 & -0.10 & 0.17 & -0.10 & 0.18 & -0.10 \\
\hline Hungary & 0.31 & -0.07 & 0.33 & -0.07 & 0.34 & -0.07 \\
\hline Latvia & 0.18 & -0.25 & 0.18 & -0.21 & 0.19 & -0.19 \\
\hline Poland & 0.28 & -0.06 & 0.28 & -0.06 & 0.28 & -0.06 \\
\hline Slovenia & 0.15 & -0.11 & 0.15 & -0.11 & 0.15 & -0.10 \\
\hline Turkey & 0.25 & -0.21 & 0.24 & -0.20 & 0.24 & -0.20 \\
\hline Romania & 0.23 & -0.26 & 0.24 & -0.27 & 0.24 & -0.28 \\
\hline Slovakia & 0.20 & -0.09 & 0.21 & -0.09 & 0.21 & -0.09 \\
\hline Estonia & 0.26 & -0.18 & 0.27 & -0.18 & 0.26 & -0.18 \\
\hline Lithuania & 0.24 & -0.23 & 0.23 & -0.23 & 0.23 & -0.23 \\
\hline Average & 0.18 & -0.11 & 0.18 & -0.11 & 0.18 & -0.10 \\
\hline
\end{tabular}

Notes: Business cycle amplitude based on the stationary bootstrap that has been described in Section 2 for different values of $p$. Figures are medians from 10,000 replications. 
Table A3. Sensitivity analysis: excess.

\begin{tabular}{|c|c|c|c|c|c|c|}
\hline \multirow{3}{*}{ Country } & \multicolumn{2}{|c|}{$\begin{array}{c}p=0.950 \\
\mathrm{E}[l]=19\end{array}$} & \multicolumn{2}{|c|}{$\begin{array}{c}p=0.970 \\
\mathrm{E}[l]=32\end{array}$} & \multicolumn{2}{|c|}{$\begin{array}{c}p=0.985 \\
\mathrm{E}[l]=66\end{array}$} \\
\hline & \multicolumn{2}{|c|}{ Excess } & \multicolumn{2}{|c|}{ Excess } & \multicolumn{2}{|c|}{ Excess } \\
\hline & Expansions & Recessions & Expansions & Recessions & Expansions & Recessions \\
\hline Austria & 0.10 & -0.02 & 0.15 & -0.02 & 0.18 & -0.03 \\
\hline Belgium & 0.02 & 0.02 & 0.03 & 0.04 & 0.00 & 0.06 \\
\hline Germany & 0.04 & -0.03 & 0.04 & -0.02 & 0.04 & -0.02 \\
\hline Greece & 0.19 & 0.08 & 0.31 & 0.08 & 0.44 & 0.06 \\
\hline Finland & 0.27 & -0.07 & 0.35 & -0.07 & 0.41 & -0.05 \\
\hline France & 0.04 & -0.04 & 0.04 & -0.05 & 0.06 & -0.05 \\
\hline Italy & 0.00 & -0.04 & -0.01 & -0.04 & -0.01 & -0.04 \\
\hline Luxemburg & 0.21 & -0.07 & 0.36 & -0.05 & 0.48 & -0.04 \\
\hline Netherlands & -0.14 & -0.10 & -0.18 & -0.12 & -0.23 & -0.14 \\
\hline Portugal & -0.18 & -0.14 & -0.28 & -0.17 & -0.42 & -0.18 \\
\hline Sweden & 0.37 & 0.02 & 0.45 & 0.04 & 0.50 & 0.06 \\
\hline UK & 0.01 & 0.04 & -0.01 & 0.07 & -0.01 & 0.14 \\
\hline Canada & 0.20 & 0.03 & 0.31 & 0.04 & 0.43 & 0.05 \\
\hline Norway & -0.13 & -0.09 & -0.07 & -0.08 & -0.07 & -0.07 \\
\hline Japan & 0.02 & 0.02 & 0.04 & 0.02 & 0.06 & 0.01 \\
\hline USA & 0.03 & -0.03 & 0.04 & -0.03 & 0.03 & -0.04 \\
\hline Spain & 0.10 & 0.00 & 0.11 & 0.00 & 0.13 & 0.01 \\
\hline Denmark & 0.10 & -0.02 & 0.13 & 0.01 & 0.23 & 0.16 \\
\hline Ireland & 0.54 & 0.06 & 0.44 & 0.07 & 0.16 & 0.06 \\
\hline Cyprus & 0.20 & 0.16 & 0.22 & 0.17 & 0.25 & 0.15 \\
\hline Czech & 0.11 & -0.08 & 0.08 & -0.09 & 0.13 & -0.11 \\
\hline Hungary & 0.73 & 0.03 & 1.03 & 0.03 & 1.29 & 0.03 \\
\hline Latvia & -0.04 & 0.27 & -0.04 & 0.20 & 0.01 & 0.19 \\
\hline Poland & 0.26 & -0.05 & 0.35 & -0.05 & 0.42 & -0.05 \\
\hline Slovenia & -0.12 & -0.03 & -0.21 & -0.04 & -0.25 & -0.06 \\
\hline Turkey & 0.03 & -0.23 & 0.08 & -0.21 & 0.14 & -0.22 \\
\hline Romania & -0.04 & 0.24 & -0.14 & 0.34 & -0.20 & 0.50 \\
\hline Slovakia & 0.14 & 0.04 & 0.18 & 0.05 & 0.19 & 0.07 \\
\hline Estonia & -0.26 & -0.14 & -0.33 & -0.15 & -0.41 & -0.15 \\
\hline Lithuania & 0.16 & -0.01 & 0.25 & 0.01 & 0.32 & 0.01 \\
\hline Average & 0.10 & -0.01 & 0.12 & 0.00 & 0.14 & 0.01 \\
\hline
\end{tabular}

Notes: Business cycle amplitude based on the stationary bootstrap that has been described in Section 2 for different values of $p$. Figures are medians from 10,000 replications. 
Figure 1: Duration, amplitude, and excess
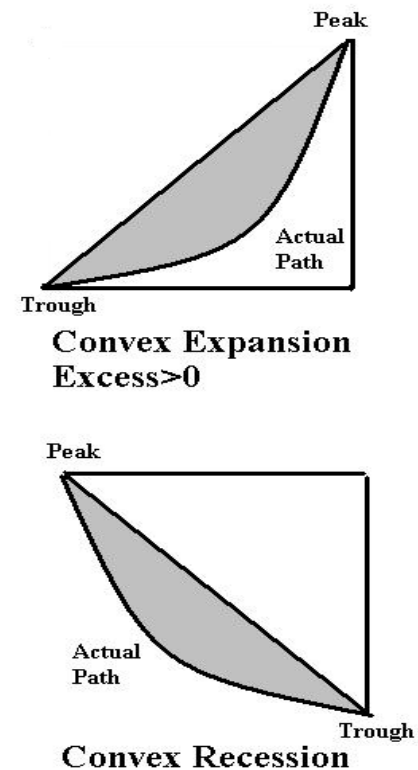

Excess $>0$
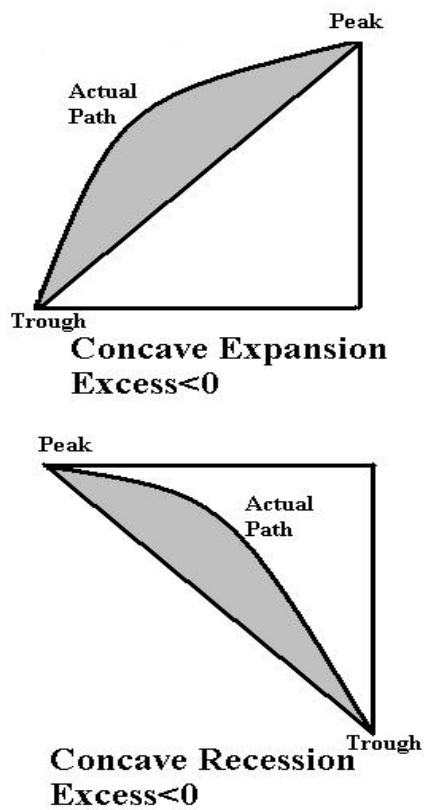

Notes. Stylized representation of typical expansions (top charts) and recessions (bottom charts). 
Figure 2: Map of business cycle characteristics

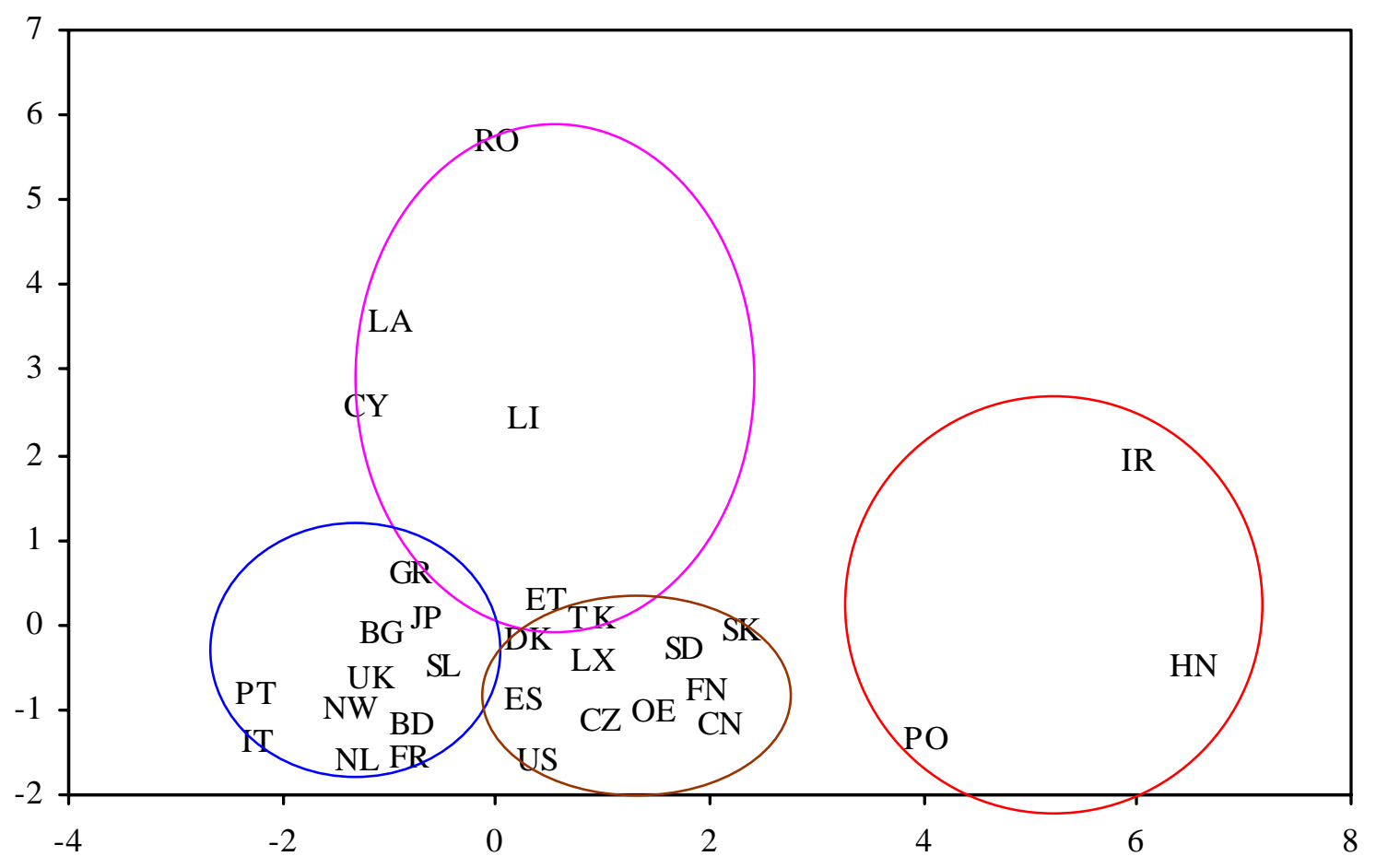

Notes. Acronyms used for the countries are specified in Section 3. This map is the multidimensional scaling map based on the Euclidean distance of the business cycle characteristics. The circles represent the clusters of countries as presented in Table 7 